\title{
PROSTORNE ANALIZE JAKIH KIŠA KRATKOG TRAJANJA NA TERITORIJI SRBIJE
}

\author{
Zoran M.Radić
}

Dragutin Pavlović ${ }^{1}$

УДК: $551.577 .22 / .37$

DOI:10.14415/konferencijaGFS 2015.080

Rezime: Osnovna pretpostavke na kojima se bazira aktuelna hidrološka praksa u Srbiji je da ne postoji prostorna homogenost jakih kiša na prostoru Srbije, a da je $i$ pretpostavka o tome da redukcione kiše važe na užim prostorima prihvatljiva samo kao nužna aproksimacija (usled nedostatka pluviografskih merenja na lokaciji od interesa).

Kako su orografski uticaji (promene nadmorskih visina na prostoru srbije) na jake kiše detaljno analizirane u drugom radu istih autora (Radić i Pavlović, 2014) i uz napomenu da je pokazano da je taj uticaj taj zanemarljiv, cilj ovog rada je provera fundamentalnih pretpostavki vezano za prostorne analize jakih kiša.

Analize su bazirane na podacima i rezultatim najnovijih obrada jakih kiša urađenih od strane RHMZS i Instituta „Jaroslav Cerni“ (VOS,2009), kao i na podacima za maksimalne dnevne padavine za Beograd na osnovu podataka iz dokumentacije Građevinskog fakulteta univerziteta u Beogradu.

Detaljnom analizom relevantnih podataka pokazano je da se, u cilju unapređenja sigurnosti objekata i dovođenja na isti nivo sigurnosti sistema za zaštite od velikih voda na čitavom prostoru Srbije, mora usvojiti novi koncept baziran na pretpostavci da se radi o maloj teritoriji sa homogenim klimatskim uslovima u pogledu jakih kiša.

Кључне речи: Hidrologija, jake kiše,regionalne analize

\section{UVODNA RAZMATRANJA}

Za hidrološku praksu statističke obrade jakih kiša su jedan od ključnih elemenata jer se na bazi njih, primenom modela za transformaciju padavina u oticaj, određuju merodavni proticaji za dimenzionisanje hidrotehničkih objekata (kišna kanalizacija, propusti, itd) i-ili merodavni poplavni talasi za dimenzionisanje preliva na branama, retenzionog prostora za prihvatanje i transformaciju poplava, isl. Računske kiše, kao ulazi modela za simulaciju oticaja, podjednako se mogu koristiti i na velikim i na malim slivovima, prem da se u praksi najčešće koriste na urbanim slivovima i manjim prirodnim slivovima bujičnog karaktera za koje su od primarnog interesa jake kiše kratkog trajanja.

\footnotetext{
${ }^{1}$ Građevinski fakultet Univerziteta u Beogradu, zradic@grf.bg.ac.rs
} 
International conference

Contemporary achievements in civil engineering 24. April 2015. Subotica, SERBIA

Pored toga, analize jakih kiša u hidrološkoj praksi se koriste i za procenu povratnog perioda jakih kiša koje su zabeležene tokom poplava.

U oba slučaja ponekad se vrši i korekcija visine ili intenziteta padavina u funkciji nadmorske visine lokacije od interesa, a redukcione krive prikazuju u analitičkoj formi, pri čemu se (na užim prostorima) određuju lokalne vrednosti parametara.

Osnovna pretpostavka na kojoj se u našoj praksi trenutno opšteprihvaćeni koncept bazira je da jake kiše (bez obzira na trajanje) imaju izrazito lokalni karakter. Drugim rečima, pretpostavlja se da ne postoji prostorna homogenost jakih kiša na prostoru Srbije, a da je i pretpostavka o tome da redukcione kiše važe na užim prostorima prihvatljiva samo kao nužna aproksimacija (usled nedostatka pluviografskih merenja na lokaciji od interesa).

Cilj ovog rada je provera navedenih fundamentalnih pretpostavki vezano za prostorne analize statistika jakih kiša trajanja kraćih od 24 sata.

\section{PODACI I PODSTICAJ}

Tokom 2014 godine Institut Jaroslav Černi je objavio monografiju „Intenziteti jakih kiša u Srbiji“ kojom je obuhvaćeno 30 pluviogradskih stanica sa podacima do 2008 godine kao i podaci o maksimalnim dnevnim padavinama za 437 kišomernih stanica na prostoru Srbije. Na žalost ova, po obimu impozantna publikacija (481 str.) u čiju realizaciju je uložen veliki rad (što je za svaku pohvalu), nije odgovorila našim očekivanjima, a usled (ne samo) štamparskih grešaka podaci sadržani u njoj nisu nisu mogli biti uzeti u razmatranje. Umesto toga, u okviru ovog rada korišćeni su podaci iz analiza jakih kiša kratkog trajanja sa 26 pluviografa (period obrade zaključno sa 2006 godinom) i analiza maksimalnih dnevnih padavina (period 1946-2006) sa 435 kišomernih stanica koje su urađene u okviru Vodoprivredne osnove republike Srbije (VOS2009.). U analize su uključene i do sada najduže serije maksimalnih dnevnih padavina za Beograd, a u komentarima i podaci o istorijskim poplavama na prostoru Srbije na osnovu podataka iz dokumentacije Građevinskog fakulteta univerziteta u Beogradu. Ipak pojavljivanje prvo navedene monografije je bilo podsticajno jer nam je dalo povoda da dublje preispitamo pojedine pretpostavke i konceptualne pristupe vezano za analizu jakih kiša na prostoru Srbije.

\section{PROSTORNI RASPORED JAKIH KIŠA}

Prostorni raspored jakiš kiša može se analizirati na bazi originalno opaženih podataka, na bazi statistika vremenskih serija opažanja ili na bazi računskih kiša za usvojenu verovatnoću pojave (ili povratni period). U nastavku su korišćena sva tri pristupa.

$\mathrm{Na}$ bazi statistika datih u okviru Vodoprivredne osnove Republike Srbije (VOS-2009.), na Slici 1 prikazane su procečne i ekstremne vrednosti srednjih vrednosti jakih kiša za 9 trajanja ( $\mathrm{u}$ rasponu od $\mathrm{Tk}=10 \mathrm{~min}$ do $\mathrm{Tk}=1440 \mathrm{~min}=1 \mathrm{~d}$ ), kao i koeficijenti varijacije srednjih vrednosti određeni na osnovu podataka za svih 26 pluviografskih stanica.

Za koeficijente varijacija (desno na Slici 1) vidi se da se vrednosti kreću u veoma uskim granicama $(0.098-0.128)$, da opadaju sa trajanjem kiša, kao i to da se zakon opadanja

\section{2}


Међународна конференција

Савремена достигнућа у грађевинарству 24. април 2015. Суботица, СРБИЈА

može opisati veoma pouzdanom regresionom zavisnošću (koeficijent determinacije je veći od 0,9$)$.

Isto tako, (videti levi deo Slike 1), skoro funkcionalne veze, (koeficijenti determinacije veći od 0,99 ), mogu se ustanoviti za porast srednjih vrednosti i maksimuma srednjih vrednosti sa povećanjem trajanja kiše. Posredno taj rezultat ukazuje da je moguće ustanoviti relativno pouzdane veze jakih kiša kraćih trajanja sa dnevnim padavinama, odnosno tzv. „redukcione krive“. Međutim, za isto trajanje kiše uočavaju se značajne razlike u ocenama srednjih vrednosti za pojedine lokacije, (videti minimalne i maksimalne vrednosti na Slici 8 -levo), što se može odraziti na značajne razlike u računskim kišama ako se proračuni sprovode za pojedine lokacije.

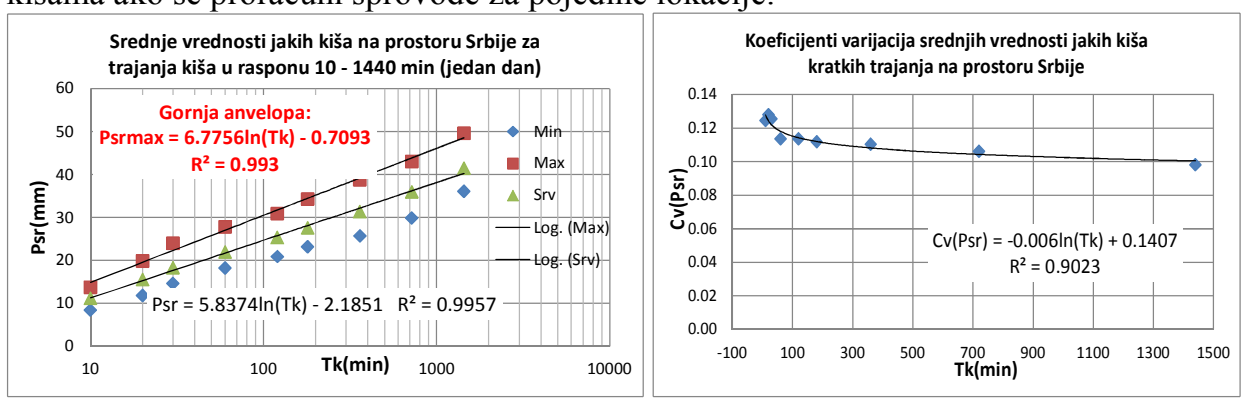

Slika 1. Opsezi promena srednjih vrednosti jakih kiša kratkog trajanja na prostoru Srbije

Na Slici 2 prikazane su prosečne i ekstremne vrednosti koeficijenata varijacije $(\mathrm{Cv})$ i koeficijenata asimetrije (Cs) dobijene na 26 pluviografa i za 9 trajanja jakih kiša trajanja kraćih od 24 sata.
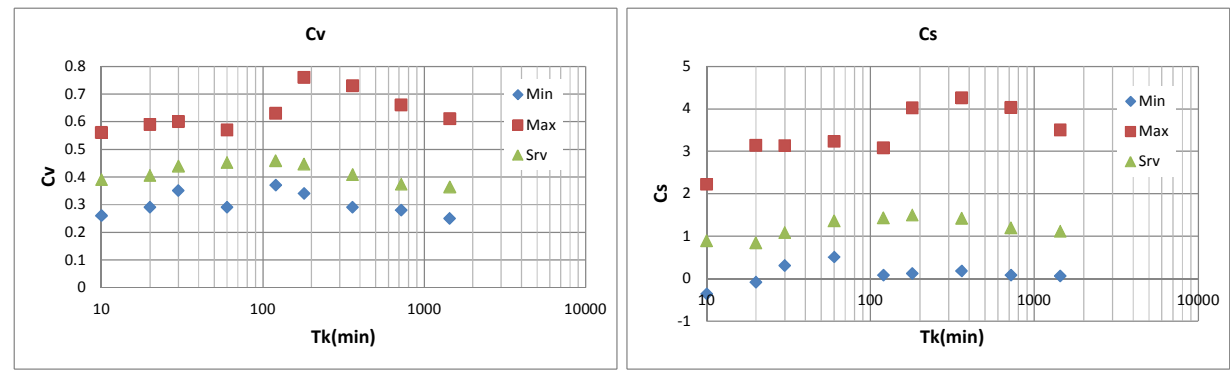

Slika 2. Opsezi promena koeficijenata varijacije i koeficijenata asimetrije jakih kiša kratkog trajanja na prostoru Srbije

Iz opseka promena statistika $\mathrm{Cv}$ i Cs (za ista trajanja kiše) uočava se značajna varijacija na pojedinim lokacijama, kao i značajna odstupanja od prosečnih vrednosti ovih parametara određenih na osnovu podataka za svih 26 pluviografskih lokacija. To samo pokazuje koliko je značajano izražen uticaj lokalnih podataka merenja na pojedinim lokacijama na kojima su smešteni pluviografi.

Globalno posmatrano varijacije srednjih vrednosti za oba parametra (Cv i Cs) i za sva razmatrana trajanja kiša kreću se u relativno uskom opsegu, što ukazuje čak i na 
International conference

Contemporary achievements in civil engineering 24. April 2015. Subotica, SERBIA

mogućnost da se za sva trajanja kiše na čitavom prostoru Srbije usvoje konstantne vrednosti, za $\mathrm{Cv}=0,42$ i $\mathrm{Cs}=1,20$.

Ipak, bez detaljnijih analiza po tom pitanju u ovom trenutku se ne mogu doneti definitivni zaključci jer se u promeni prosečnih vrednosti parametara $\mathrm{Cv}$ i Cs sa trajanjem kiše uočavaju i neke zakonomernosti. Tako npr., zapaža se da su karakteri promena $\mathrm{Cv}$ i Cs za kiše trajanja do $60 \mathrm{~min}(1 \mathrm{~h})$ drugačiji od onih čije je trajanje duže od $3 \mathrm{~h}$ (180 min). Ovo je verovatni razlog što se kod definisanja krivih I-T-P (ili H-T-P) redovno javljaju prelomi za kiša trajanja oko 90 min.

Predhodno prikazane varijacije osnovnih statističkih parametara direktno se odražavaju i na računske jake kiše. Ovo je ilustrovano na Slici 3 na kojoj su prikazane računske kiše verovatnoće pojave $\mathrm{p}=1 \%$ (povratni period $\mathrm{T}=100$ god) za 9 trajanja kiše (kao i prethodno) na svih 26 lokacija pluvigrafa.

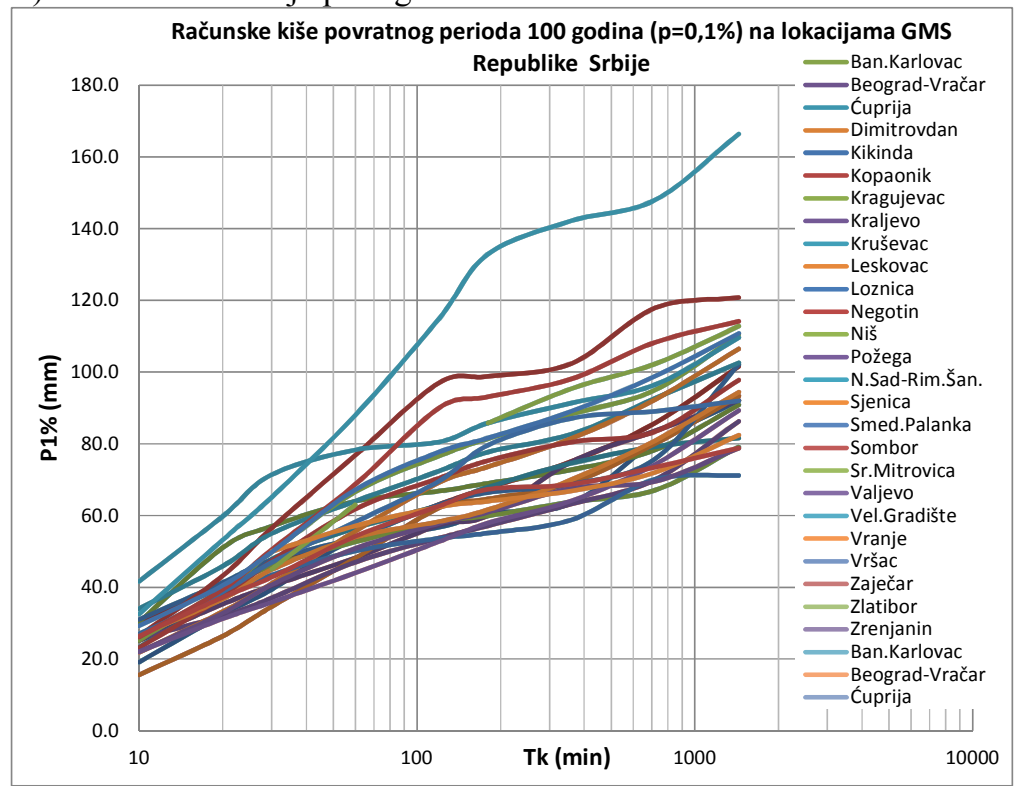

Slika 3. Računske kiše $e^{2}$ verovatnoće pojave $p=1 \%$ (povratni period $T=100$ god) za 9 trajanja na 26 lokacija pluvigrafa na prostoru Srbije

Sa Slike 3 se vidi da postoje značajna odstupanja na pojedinim lokacijama. Najveće vrednosti dobijene su na lokaciji „Vršac“ za trajanja od 60-1440 minuta, zatim „Smederevska Palanka“" na kojoj su dobijeni maksimumi za trajanja 10-30 minuta, a nakon toga značajnije od ostalih vrednosti odstupaju i maksimumi za „Kraljevo“i „Valjevo“. Što se najnižih vrednosti tiče, za trajanja 10-30 minuta izdvaja se" Kopaonik", za trajanja 60120 minuta „Vranje“, za trajanja 180-360 minuta „Niš“, za trajanje 720 min „Kruševac“

\footnotetext{
${ }^{2} \mathrm{U}$ okviru statističke analize maksimalnih dnevnih padavina urađene u VOS (2010.), na 73 od 435 kišomernih stanica (u $17 \%$ slučajeva)uočeni su izuzeci pa je izvršena korekcija verovatnoća. Nije navedeno o kom tipu izuzetne vrednosti se radi kao ni to kako su vršene korekcije verovatnoća, ali je interesantno da su te korekcije urađene za podatake na 6 od 26 lokacija (u $23 \%$ slučajeva) na kojima se nalaze i pluviografi.
}

\section{4}


Међународна конференција

Савремена достигнућа у грађевинарству 24. април 2015. Суботица, СРБИЈА

i za trajanje 1440 minuta ponovo „Niš““. Napominjemo da računske vrednosti preuzete iz VOS-2010, gde za trajanja 10,20 i 120 minuta nedostaju podaci za „Veliko Gradište“, kao i vrednost za trajanje 20 minuta na lokaciji „Zaječar“.

Pitanja koja se logično nameću su:

- Da li su uočene razlike od lokacije do lokacije rezultat stvarne prostorne neravnomernosti jakih kiša na prostoru Srbije?

- $\quad$ Koliki je uticaj obima raspoloživih uzoraka i kakav uticaj na finalne rezultate imaju pojedine (ekstremne kiše) koje su registrovane samo na pojedinim lokacijama (jake kiše lokalnog karaktera)?

U nastavku će se prikazati samo neki brojčani pokazatelji koji idu u prilog formulacije odgovora na postavljena pitanja, ograničavajući se samo na podatke o dnevnim maksimumima padavina jer se za njih raspolagalo sa najviše informacija, uz napomenu da usled dokazane veze 24-časovnih (dnavnih) sa kišama kraćeg trajanja zakključci imaju opšti karakter.

a. Već na osnovu prethodno izdvojenih lokacija na kojima računske kiše kratkih trajanja značajnije odstupaju od ostalih ( „Vršac“, ,,Smederevska Palanka“, , Kraljevo “ $i$,,Valjevo“), jasno se vidi da nema prostorne uniformnosti. Ovo potvrđuju i podaci o lokacijama opaženih maksimuma za pojedina trajanja. Tako, npr., prema podacima VOS (period obrade 1946-2006.) na prostoru Srbije absolutno maksimalne dnevne „količine“ padavina zabeležene su na sledećim lokacijama: „Rakov Do" $220 \mathrm{~mm}$, ,Negotin“ $211.1 \mathrm{~mm}$, ,Vršac" 189,7 mm, ,Lazarevac“ 173,6 mm, „Vajska“ 162,4 mm i „Jabukovac“ 162,3 mm. Rasutost lokacije ovih stanica po prostoru Srbije, kao i razlike u odnosu na ranije navedene lokacije u kojima se javljaju maksimalne računske kiše (izuzetak je samo Vršac), jasno ukazuju da nema prostorno homogenih (užih) područja u kojima se eksluzivno javljaju jake kiše. To je u absolutnom skladu sa trvrdnjom Profesora Vujice Jevđevića izrečenom na predavanju koje je 1990 godine održao na Građevinskom fakultetu u Beogradu: „Izuzetne padavine koje su već registrovane na jednom mestu sigurno će se javiti i na drugom - samo je pitanje vremena kada će se to desiti“.

$\mathrm{Na}$ neophodnost sagledavanja ekstremnih padavina na širim prostorima jasno ukazuju i sledeći primer. Maksimalno opažene dnevne padavine u periodu 19462006. godine na lokalitetima „Niš““, „Leskovac“ i „Dimitrovgrad“ su (respektivno) Pmaxld=77 mm, $92 \mathrm{~mm}$ i $123 \mathrm{~mm}$. Sa prethodno navedenim vrednostima kao repernim (jer odgovaraju najvišoj empirijskoj verovatnoći), za računske kiše $\mathrm{T}=100$ $\operatorname{god}(\mathrm{p}=1 \%)$ i trajanje $\mathrm{Tk}=1440 \mathrm{~min}=1 \mathrm{~d}$ na razmatranim lokacijama pluviografa dobijene su vrednosti: „Niš $\mathrm{P}=71,2 \mathrm{~mm}$, „Leskovac“ $\mathrm{P}=86,3 \mathrm{~mm}$ i „Dimitrovgrad“ $\mathrm{P}=92,1 \mathrm{~mm}$. Dakle, sistemi zaštite od 100-godišnjih voda u razmatranom prostoru i zavisno od lokacije, dimenzionisao bi se na osnovu proticaja od računskih kiša koje se kreću u rasponu 71-92 mm, odnosno sa razlikom do $21 \mathrm{~mm}$ (više od 20\%). U svakom slučaju računske 100-godišnje dnevne padavine bi bile manje od $93 \mathrm{~mm}$. Međutim, na reci Vlasini koja se nalazi u u trouglu koje formiraju izdvojeni lokaliteti, tokom poplave 26 Juna 1988 godine na četri druga lokaliteta: „Brestov Do“, „Kijevac“, „Radinjice“ i „Rakov Do“ već je izmereno Pmaxld= 128,8 mm, $130,5 \mathrm{~mm}, 150 \mathrm{~mm}$ i $220 \mathrm{~mm}$, a te vrednosti nemaju nikakvog uticaja na računske 
International conference

Contemporary achievements in civil engineering 24. April 2015. Subotica, SERBIA

kiše za naselja Niš, Leskovac i Dimitrovdan, kao ni na okolnim slivovima Južne Morave i Nišave. Sa druge strane,(znajući da anvelope maksimalno opaženih padavina približno odgovaraju 100-godišnjem periodu računskih vrednosti), i u okviru samog sliva reke Vlasine po aktuelno prihvaćenoj metodologiji (vezivanja za redukcione krive sa najbližeg pluviografa i za lokalnu statistiku dnevnih kiša za najbližu kišomernu stanicu) dobile bi se drastične razlike u vrednostima računskih kiša za veoma bliske lokacije. Slični primeri mogu se izvesti i sa podacima za druge regione na prostoru Srbije, pa je svaki dalji komentar izlišan.

b. Uticaj obima uzorka na vrednost statistika analiziran je na bazi podataka o dnevnim maksimumima padavina za Beograd-Vračar, jer na toj lokaciji postoje najduže serije merenja. Uporedne vrednosti statistika prikazane su u Tabeli 1.

Tabela 1. Uporedni pregled statistika maksimalnih dnevnih padavina za Beograd-

Vračar na osnovu različitih, raspoloživih izvora podataka

\begin{tabular}{|c|c|c|c|c|c|c|c|c|}
\hline Period & $\mathrm{N}$ & Psr & Stdev & $\mathrm{Cv}$ & Cs & Pmin & Pmax & Napomene \\
\hline \multicolumn{9}{|c|}{ 1. Podaci na osnow pluviografa za $\mathrm{Tk}=1440 \mathrm{~min}(1 \mathrm{~d})$} \\
\hline 1946.-2008. & 63 & 42.64 & 16.63 & 0.39 & 0.86 & & 88.4 & VOS-2010 (max. sa dijagrama) \\
\hline \multicolumn{9}{|c|}{ 1. Podaci iz Vodoprivedne osnove Republike srbije } \\
\hline 1946.-1991. & 46 & 44.00 & 16.35 & 0.37 & 0.99 & 19.8 & 88.4 & VOS-1996 (max.opažen 1951.) \\
\hline $1946 .-2008$. & 63 & 44.52 & 16.85 & 0.38 & 1.12 & 19.8 & 94.0 & VOS-2010 (max.opažen 1994.) \\
\hline \multicolumn{9}{|c|}{ 2. Podaci iz dokumentacije Građevinskog fakulteta u Beogradu } \\
\hline 1888.-1891.(bez 1895.) & 11 & 46.06 & 20.91 & 0.45 & 1.31 & 26.8 & 92.4 & N.Stamenković (max.opažen 1900. \\
\hline $1923 .-2012$. & 90 & 44.20 & 16.50 & 0.37 & 1.18 & 19.8 & 94.0 & Max.opažen 1994. \\
\hline Maj 2014 & 1 & & & & & & 108.0 & Do sada opaženi abs.max. \\
\hline \multicolumn{9}{|c|}{ 3. Podaci za spojene serije (agregacija) } \\
\hline 1923.-2012. sa 2014. & 91 & 44.90 & & & & & & Novi max.izazvao skok Psr za 0,7 \\
\hline Rasp.od 1888. do 2014 & 102 & 45.03 & & & & & & Srbija: Pros. 41.46; Max. 49.54mm \\
\hline
\end{tabular}

Prosečne vrednosti serija dnevnih maksimuma za Beograd (Psr), u zavisnosti od izvora podataka i dužine serija kreću se u rasponu Rasp=3.42 mm (Psr=42.64-46.06 mm), a na osnovu svih raspoloživih podataka iz perioda 1888.-2014. godine srednja vrednost godišnjih maksimuma dnevnih padavina određena na bazi uzorka ukupnog obima $\mathrm{N}=102$ godine je $45.03 \mathrm{~mm}$. To je za 3,57 mm veće od proseka za Srbiju (Psr=41.46 $\mathrm{mm}$, određeno na bazi podataka sa svih 26 pluviografa), ali je takođe čak za $4.51 \mathrm{~mm}$ niže od maksimuma srednje vrednosti koja je dobijena na prostoru Srbije (Psr=49.54 mm dobijeno za „Zlatibor").

Statistički posmatrano, statistička vrednost (npr. srednja vrednost) određena na osnovu uzorka obima 102 godine trebalo bi da je više nego pouzdana. Međutim, podaci prikazani u Tabeli 1 pokazuju da samo jedna vrednost ekstremnih padavina (u konkretnom slučaju $P d n=108$ mm iz Maja 2014) u seriji sa 90 podataka može podići srednju vrednost približno $1 \mathrm{~mm}$ (u konkretnom slučaju tačno 0,7 ), pa se, imajući u vidu da su u bližem ili daljem okruženju tokom zadnjih 60 -tak godina u više od 15 slučajeva $^{3}$

\footnotetext{
${ }^{3}$ Osim na 6 lokacija na kojima su opaženi dnevni maksimumi u rasponu 162-220 mm, to su i sledeća merenja: „Loznica“ Pmd=110 mm, ,Kopaonik“ Pmd=111 mm, „Kragujevac“ Pmd=112 mm, „Veliko Gradište“ Pmd=113 mm, „Požega“ Pmd=115 mm, „Negotin“ Pmd=116 mm, „Dimitrovgrad“ Pmd=123 mm, „Kraljevo“ Pmd=124 mm, „Smed. Palanka“ Pmd=129 mm, itd.
}

\section{6}


Међународна конференција

Савремена достигнућа у грађевинарству 24. април 2015. Суботица, СРБИЈА

opaženi dnevni maksimumi koji prevazilaze opaženi absolutni maksimum u Begradu $(108 \mathrm{~mm})$, postavlja pitanje pouzdanosti ovako procenjene („lokalne“) srednje vrednosti. To postaje još dramatičnije ako se zna da na prostoru grada Beograda, (na pluviografu „Bela Reka“ u slivu Topčiderske reke 29.08.1988. godine tokom kiše koja je trajala 15 sati), već registrovano $\mathrm{Pdn}=121,6 \mathrm{~mm}^{4}$.

Ako se za trenutak zanemari okruženje i statistički analizira pouzdanost procena srednje vrednosti maksimalnih dnevnih padavina za Beograd, i na osnovu Tabele 1 usvoje sledeće, orijentacione vrednosti parametara: $\mathrm{Psr}=45.03 \mathrm{~mm}, \mathrm{Stdev}=16,5 \mathrm{~mm}, \mathrm{Cs}=1.18$ dobijaju se sledeće procene:

- Uzoračka ocena za N=102 godine Psr1d=45.03 mm

- Gornja granica intervala poverenja 95\% pretpostavljajući da su srednje vrednosti populacije distribuirane po Normalnoj raspodeli Psrld $=48.44 \mathrm{~mm}$

- Gornja granica intervala poverenja 95\% predpostavljajući Gumbelovu raspodelu (jer je uzoračka vrednost $\mathrm{Cs}=1.18$ bliska $\mathrm{Cs}_{\mathrm{s}}=1,13$ ) $\mathrm{Psrld}=49.23 \mathrm{~mm}$

- Gornja granica intervala poverenja $95 \%$ po Pearson-3 raspodeli za $\mathrm{Cs}=1,18$ (približna interpolacija po tabelama iz knjige S.Jovanovića) Psr1d $=49.55 \mathrm{~mm}$.

Očigledno je, da imajući u vidu uzoračku vrednost Cs, kao merodavna treba usvoji zadnje prikazanu procenu. Može se primetiti da je ta procena, $\mathbf{P s r}=\mathbf{4 9 . 5 5} \mathbf{~ m m}$, skoro identična sa maksimumom dobijenim na bazi svih 26 pluviografa na prostoru Srbije koja iznosi Psr=49,54 mm (zadnja vrednost u Tabeli 1).

Ako je za lokaciju koja ima 102 godine opažanja pokazano da postoji značajna neizvesnost procena statistika, onda je jasno da ona mora postojati i u serijama sa pluviografa čije su serije, sa opažanjima od početka rada zaključno sa 2008 godinom dužine $\mathrm{N}=17-59$ godina (prosek za 30 stanica je 47 godina), kao i u procenama dnevnih maksimuma sa N=61godina (period obuhvaćen VOS-2009 je 1946-2006 godine, uz napomenu da se on se ne poklapa sa istorijatom rada pojedinih kišomernih stanica).

\section{ZAVRŠNA RAZMATRANJA, ZAKLJUČCI I PREPORUKE}

Prethodno prikazani komentari u vezi maksimalno opaženih dnevnih padavina na prostoru Srbije, kao i procene mogućih varijacija srednje vrednosti za lokaciju BeogradVračar gde se raspolaže sa najdužim serijama opažanja dnevnih maksimuma, jasno pokazuju u kom smeru treba orijentisati buduće analize jakih kiša ukoliko je težnja da se pouzdanosti objekata za zaštitu od poplava i funkcionalna sigurnost ključnih infrastrukturnih objekata u Srbiji dovede na ujednačeni i zadovoljavajući nivo.

Pri tome treba razmatrati dve opcije:

\footnotetext{
${ }^{4}$ Na k.s. „Beograd-Vračar“ su tokom 90 godina (period: 1923.-2012.) registrovane Pmax1d=94 mm i Pmax2d=136 mm. Ove vrednosti su prevaziđene tokom poplava iz Maja 2014 godine kada je zabeleženo Pmax1d=108 mm i Pmax2d=153 mm. Međutim, na p.s."Bela Reka“ zabeležene vrednosti Avgusta 1985 godine: Pmax1d=121,6 mm i Pmax2=201,8 mm, su bile znatno veće.

Zadnje navedeni podaci prevazilaze i absolutno zabeležene maksimume za ista trajanja koja su tokom poplava iz Maja 2014 godine registrovana na k.s."Loznica“ (Pmax1d=110 mm i Pmax2d=163 mm), kao i absolutne maksimume za ista trajanja iz regiona (Pmax $2 \mathrm{~d}=185 \mathrm{~mm}$ registrovano na k.s."Tuzla“).
} 
A. Usvojiti realnu pretpostavku da su maksimalne padavine potpuno slučajne promenljive, (sa podjednakom šansom da se već opažene vrednosti na jednoj lokaciji sasvim izvesno mogu pojaviti i na bilo kojoj drugoj na prostoru Srbije), u kom slučaju za ocene srednjih vrednosti jakih kiša određenih trajanja treba usvojiti vrednosti sa gornje anvelope za Srbiju sa Sike 1-levo, ili

B. Pretpostaviti homogenost statističkih parametara jakih kiša na čitavom prostoru Srbije, pa kao merodavne usvojiti srednje vrednosti sa Slike 1-levo uz korekcije na gornju granicu intervala poverenja $95 \%$.

Pristup A garantuje značajna povećanja računskih kiša za sva trajanja kiša na većini lokacija (što je na strani sigurnosti), dok je pristup B možda za naše praktičare prihvatljiviji jer je analogan sa već prihvaćenim analizama koje se rade sa protocima (usvajanje merodavnih vrednosti na bazi intervala poverenja).

Fundamentalna razlika ovde predloženog pristupa u odnosu na postojeću praksu je ta što se napušta pretpostavka da su jake kiše za svaku lokaciju na prostoru Srbije različite, odnosno da se pretpostavlja da je čitav prostor Srbije jedna homogena zona, a da su uočene razlike koje se dobijaju na osnovu tačkastih merenja rezultat nereprezentativnosti uzoraka nastalih usled kratkoće merenja na toj lokaciji i prostorno-stohastičkog karaktera pojave jakih kiša.

\section{ZAHVALNOST}

Rezultati prikazani u ovom radu su deo istraživanja u okviru projekata TR37010 i TR43007 koje finansira Ministarstvo nauke Republike Srbije, kojem se autori ovim putem zahvaljuju na podršci.

\section{ЛИТЕРАТУРА}

[1] Institut za vodoprivredu „Jaroslav Černi” i RHMZS: Vodoprivredna osnova Republike Srbije - Hidrološke podloge, 2009.

[2] Jovanović, S.: Primena metoda matematičke statistike u hidrologiji, Građevinski fakultet univerziteta u Beogradu,Beograd 1987.

[3] Radić, M.Z.(editor): Nagle poplave -uzroci i posledice, JDH i JKMHP,Zbornik radova sa savetovanja JUSOP'89 Kopaonik 19-21.12.1988, SHMZ, Beograd 1988.

[4] Stamenković, N.: Osnovi hidrotehnike od Gustava Tolkmita, Štampano u srpskoj državnoj štampariji, Београд, 1900. 
Међународна конференција

Савремена достигнућа у грађевинарству 24. април 2015. Суботица, СРБИЈА

\section{SHORT HEAVY RAIN AERIAL ANALYSES IN SERBIA}

Summary: Heavy rain aerial analyses in Serbia are based on data from 26 pluviometrique stations, 435 rain-gauges, long series of maximal daily data for Belgrade and rainfall which caused the exteme floods in Serbia.

It is shown that existing practice based on local data sets is hyghly uncertain and new approach based on regional data analyses is proposed.

Keywords: Hydrology, heavy rain, regional analyses 